\title{
Florence Nightingale and the early origins of evidence-based nursing
}

Florence Nightingale is now a much ignored historical figure. The publication of the Collected Works of Florence Nightingale by Wilfred Laurier University Press, beginning in 2001, will outline her enormous contribution not only to the foundation of the nursing profession but also to the establishment of a public healthcare system. The Collected Works will include her published works and many unpublished letters and notes. Not the least of the areas where quite a new Nightingale will appear is in evidence-based nursing, a term that was not in use in her day, but a concept central to her own theory of nursing and health care.

\section{A passionate statistician}

Let's begin by looking at Nightingale as a systemic thinker and a "passionate statistician." Her work in nursing and social reform was informed by a religious faith or philosophy that favoured a systemic approach: God made the world and runs it by laws, which we can discover by research in both the biophysical and social spheres. For Nightingale, this entailed the best possible research, access to the best available government statistics and expertise, and the collection of new material where the existing stock was inadequate. Nightingale's leadership style was very much knowledge based.

She herself was a pioneer developer of survey instruments, always vetted by other experts and pretested on appropriate cases. She was also a pioneer in the graphical presentation of data. At a time when research reports were only beginning to include tables, Nightingale was using bar and pie charts, which were colour coded to highlight key points (eg, high mortality rates under certain conditions). Nightingale was keen not only to get the science right but also to make it comprehensible to lay people, especially the politicians and senior civil servants who made and administered the laws.

\section{Evidence-based practice}

Several examples clearly reflect an evidence-based framework, ranging from Nightingale's first work after her return as a heroine from the Crimean War in 1856, to a late attempt to influence social policy with a proposal for a chair in "social physics" at Oxford University in 1891. These examples will be described briefly.

\section{SYSTEMATIC DATA COLLECTION}

Nightingale returned from the Crimean War with a conviction that the desperate loss of life she witnessed should never occur again. She pressed for the creation of a royal commission to investigate the causes of the high mortality (eg, for every 1 soldier that died from his wounds, 7 died from disease). She worked with a team of "sanitary experts," including William Farr, who was Britain's leading social statistician at the time. The royal commission report that was eventually produced showed Nightingale's work from its conception, terms of reference, choice of members, and analysis of data to its recommendations for change. ${ }^{1}$ One recommendation was for the creation of a statistical department to track rates of disease and mortality and to identify problems so that they could be dealt with promptly.
Nightingale found another opportunity to achieve reforms during the 1860 International Statistical Congress, which was held in London and presided over by the eminent Belgian statistician, Adolphe Quetelet. She sent a letter advocating the uniform collection of hospital statistics, so that outcomes could be compared by hospital, region, and country. ${ }^{2}$ The delegates took up her proposal, adopted a resolution to that effect, and forms were duly drawn up. Jocelyn Keith described the proposal as "the first model for the systematic collection of hospital data using a uniform classification of diseases and operations that was to form the basis of the ICD code used today." Nightingale sent a proposal for improved statistics of surgical operations to the International Statistical Congress held at Berlin in 1863, which took the analysis a step further.

Nightingale attempted unsuccessfully to have the census modified to make it a more effective source of data for public policy. As the 1861 census was being prepared, she tried to have questions on health status and housing added, conscious that health outcomes were influenced by housing. A question on health would provide information that mere mortality data did not: "We should have a return of the whole sick and diseases in the United Kingdom for one spring day, which would give a good average idea of the sanitary state of all classes of the population."

\section{EXPLORING DIFFERENTIAL MORTALITY AMONG POPULATION SUBGROUPS}

When Nightingale became acquainted with the literature on the high mortality rates of aboriginal peoples, which raised the possibility of entire races dying out, she persuaded the Colonial Office to send out questionnaires to obtain data on mortality rates in colonial schools and hospitals. She analysed the results herself, "scrofulous returns" as she described them. ${ }^{5}$ Because the data were so poor and the methods of collection so disparate, she could only make the most cursory observations. It seemed that the mortality rate of native children at schools was "double that of English children of the same ages." ${ }^{\prime 6}$ Moreover, most mortality was the direct result of preventable diseases. She pleaded for the systematic collection of data that could be used for comparative purposes.

\section{CARE BY TRAINED OR UNTRAINED NURSES}

One of Nightingale's most important contributions was to address the institution of professional nursing services in workhouse infirmaries, which were appalling institutions with scant medical care and only untrained "pauper" nurses, themselves workhouse inmates, supposedly to give nursing care. The first attempts to establish nursing care provided by trained nurses in a workhouse infirmary occurred in 1865 in Liverpool, thanks to funding provided by a Christian philanthropist, William Rathbone, Nightingale's vision and drive, and the superintendence of a St Thomas' Hospital trained nurse, Agnes Jones, who died of typhus on the job only a few years later.

Nightingale and Rathbone believed that if care by trained nurses could be shown to be successful, the authorities would be forced to extend it to other workhouses. Before they could make 
this case, however, data were brought forward apparently to prove that mortality rates had not dropped as a result of the reforms. Because professional nursing had not been introduced in all the wards, the rates could be compared between those with and those without professional nursing. Nightingale's reaction was that "much injury has been done to the cause by putting forward figures at all as a test of nursing efficiency. Hospital statistics represent first and primarily the effects of the sanitary state of the hospital....next the severity of the cases. After this is determined they represent the result of different operations and different modes of treatment, and after all these constants are determined they may represent the dieting, nursing and general management, but in your Liverpool case they represent nothing, because they have never been kept with reference to any result."

She explained that the purpose of the statistics was to compare mortality rates associated with care from trained and untrained nurses of similar cases in hospital, which was clearly not the case in Liverpool. There had been no random assignment of similar cases between the wards with and without professional nursing, and indeed one might suspect that the more severe cases might have been assigned to the wards with trained nurses.

\section{EXPLORING EXCESS MORTALITY AFTER CHILDBIRTH}

Nightingale's landmark study of maternal mortality from puerperal fever is a formidable example of evidence-based decision making in health care. Nightingale in fact closed the midwifery ward and the training school associated with it on the basis of excessive rates of maternal mortality, even though the rates were lower than those in many continental institutions. ${ }^{8}$ Although some data were available on maternal mortality from puerperal fever, Nightingale was concerned with their lack of comparability, especially the different lengths of stay in different institutions. There were also problems of how to count deaths from puerperal fever acquired at an institution, but not occurring until after the woman had been discharged. Nightingale sent questionnaires to institutions to try to ascertain the "normal mortality rate" associated with childbirth. It would then be possible to see if the rate at any particular institution was excessive. The results were clear enough: "With all their defects, midwifery statistics point to one truth, namely that there is a large amount of preventable mortality in midwifery practice, and that, as a general rule, the mortality is far, far greater in lying-in hospitals than among women lying-in at home." Mortality rates could also be influenced by the age of the mother, number of pregnancies, duration of labour, the general state of the place of delivery and length of time kept in it, and such social factors as social class, health, and stamina. It might be expected that women in workhouses, because of their poverty and generally worse health, would have higher mortality rates than women giving birth in regular midwifery institutions. But this did not occur, and Nightingale concluded that the effect of the institution on mortality rates, especially the presence of medical doctors and students, was greater than that of social conditions.

USING EVIDENCE TO GUIDE POLICY DECISIONS

Late in life, Nightingale returned to her concern that statistical knowledge should guide public policy. She tried to have a chair or readership established at Oxford University, where most senior civil servants and politicians were educated, to teach "social physics" or applied statistics. She was prepared to contribute
$£ 2000$ to fund it. She approached the distinguished eugenics expert, Sir Francis Galton, to take the matter to the university, but he never really understood her goal. He was prepared to use her money for an essay contest, which Nightingale felt would not be worth the trouble. ${ }^{10}$ She explained that, by then, data were routinely collected by government departments. The problem was the failure to use it in decision making: "Our chief point was that the enormous amount of statistics at this moment available at their disposal (or in their pigeon holes which means not at their disposal) is almost absolutely useless. Why? Because the Cabinet ministers...their subordinates, the large majority of whom have received a university education, have received no education whatever on the point upon which all legislation and all administration must-to be progressive and not vibratory-ultimately be based. We do not want a great arithmetical law; we want to know what we are doing in things which must be tested by results." 11

It is unfortunate that Nightingale's proposal was not acted on, for it would have undoubtedly led to the earlier and better use of evidence in public policy, health care, and other matters.

The Collected Works of Florence Nightingale will report on many other examples of Nightingale's work in these areas. The Collected Works will also make it possible to revisit a common interpretation and criticism of Nightingale's "failure" to spend more time on the training school at St Thomas' Hospital. It is true that she did not immediately set to work on the establishment of the school, nor did she ever devote most of her working time to it. But her commitment to nursing was always as a means to an end: the more lives saved the better. When Nightingale returned from the Crimean War, she considered the reform of War Office measures for the care of the sick and wounded her top priority. Subsequently, she became aware of high rates of preventable death in India and for the rest of her life she gave more time to India than to nurse training at $\mathrm{St}$ Thomas'. In other words, Nightingale's own decisions as to how best to use her time and energy were based on the best available evidence.

LYNN McDONALD, PhD Department of Sociology and Anthropology University of Guelph Guelph, Ontario, Canada

Lynn McDomald is the project director of the Collected Works of Florence Nightingale.

1 Report on the sanitary condition of the army. London: HMSO, 1858. See also F. Nightingale. A contribution to the sanitary history of the British army during the late war with Russia. London: John Parker, 1859.

2 Nightingale, F. Letter to the International Statistical Congress, 19 July 1860. In McDonald L, editor. Women theorists on society and politics. Waterloo: Wilfrid Laurier University Press 1998:179-80.

3 Keith JM. Florence Nightingale: statistician and consultant epidemiologist. International Nursing Review 1988;35:147-50.

4 Nightingale F. Letter to William Farr, 21 April 1860. Wellcome Trust MS $5474 / 18$.

5 Nightingale F. Letter to William Farr, 28 April 1860. Add Mss $43398 \mathrm{fl} 180$.

6 Nightingale F. Sanitary statistics of native colonial schools and hospitals. Transactions of the National Association for the Promotion of Social Science 1863:477.

7 Nightingale F. Letter to Charles Langton, September 1868. Add Mss 45801 f123.

8 McDonald L. Women founders of the social sciences. Ottawa: Carleton University Press, 1994:202-05.

9 Nightingale F. Introductory notes on lying-in institutions. London: Longmans, Green, 1871:3.

10 Pearson K, editor. Life, letters and labours of Francis Galton. Cambridge: Cambridge University Press, 1924;2:424.

11 Nightingale F. Letter to Benjamin Jowett, 3 January 1891. Add Mss 45785 f144. 